\section{THE DRAINING OF BINLEY LAKE AND ITS ECOLOGICAL CONSEQUENCES}

\section{By Wing-Commander T. R. CAVE-BROWNE-CAVE,} C.B.E.*

$\mathrm{A}$ DESCRIPTION of the formation of drainage channels in the mud exposed by draining a large lake and the exceptionally rapid growth of vegetation on the lake bed may be of some general interest. The work was done for camouflage during the War.

A large expanse of water is the most outstanding landmark seen from the air at night. To an airman who knows how to approach it from the correct quarter in suitable conditions of light, it will shine out in sharp contrast with the general darkness of the landscape. A few miles to the east of Coventry is Binley Lake, some 90 acres in extent, and of a most distinctive horse-shoe shape. It would be an invaluable landmark to an enemy approaching a target so far from the coastline. It was therefore decided, after consultation with the Air Staff, to drain the Lake in order to suppress its outstanding appearance.

The Lake contained a great quantity of coarse fish, and the owners derived very considerable revenue from fishing. But their co-operation was prompt and most helpful. A stream flowed into one end of the Lake. Water passed out through sluices so placed that the Lake would drain without difficulty when they were fully opened. Arrangements were made with the Fishery Board of the area to net the fish and transfer them to streams and reservoirs in the neighbourhood. The experts who did the work estimated that they successfully decanted nearly a million fish, ranging from pike of more than $20 \mathrm{lb}$. to bream of about $20 \mathrm{gm}$. The netting process necessitated lowering the water-level very slowly. When most of the important fish were out, the last of the water was released. That left ninety acres of flat wet mud which would shine and reveal the distinctive shape just as well as the water would have done. Even if the bed did dry out during the summer, it would return to its wet brilliance after every heavy rain storm. It was considered that not until the mud was well drained and aerated after several seasons would there be any strong growth of vegetation. The mud was very soft and 4-6 ft. deep. Any work of artificial drainage would have been almost impossible. There was, however, such a complete absence of those drainage channels which appear in mud flats left by the tide in an estuary that it seemed worth while to arrange for another 'tide', which ebbed more rapidly.

The Lake was allowed to refill to a depth of some 12 inches. The sluices were then opened wide, so as to get the maximum possible rate of outflow. In less than

* Of University College, Southampton, late Director of Camouflage. two hours, a perfect system of drainage channels started to develop and gradually spread over the whole area in perfect pattern. It was therefore probable that the mud would gradually dry out and would not re-flood, because rain storms would tend to cut the channels deeper. Fig. 1 is from a photograph taken on November 13, 1942, from the outlet sluices, a few hours after drainage was complete.

The site was examined occasionally from the air until it was obvious that the mud had dried so well that there was no risk of shine. It was not until some eight months later-November to July-that a further survey was made. The report was rather surprising, so an examination on the ground was made. The lake bed was completely covered by dense vegetation. Fig. 2 is from a photograph taken on September 22, 1943, from the same point as Fig. 1, but ten months later and in a slightly different direction. The expanse of supposedly waterlogged and sterile mud was covered with a dense growth, including some willows more than $8 \mathrm{ft}$. high. Presumably the drainage and aeration had been rather better than expected. The crust had hardened sufficiently to allow men to walk across the Lake with circumspection; but there was a pronounced jelly-like movement which suggested the mud underneath.

There can be no doubt of the excellence of the camouflage. The cost of making the change was small. It may be significant that, although Coventry had been heavily raided on two occasions previous to the draining, two raiders which came to that area not long after the Lake was drained dropped their bombs in open country within ten or fifteen miles of the vitally important area.

After the need for camouflage had ceased, the problem of returning the Lake to its owners and determining the extent of compensation arose. Expert advice was taken upon the action which would most promptly enable the lake bed to return to a condition in which the Lake could satisfactorily be

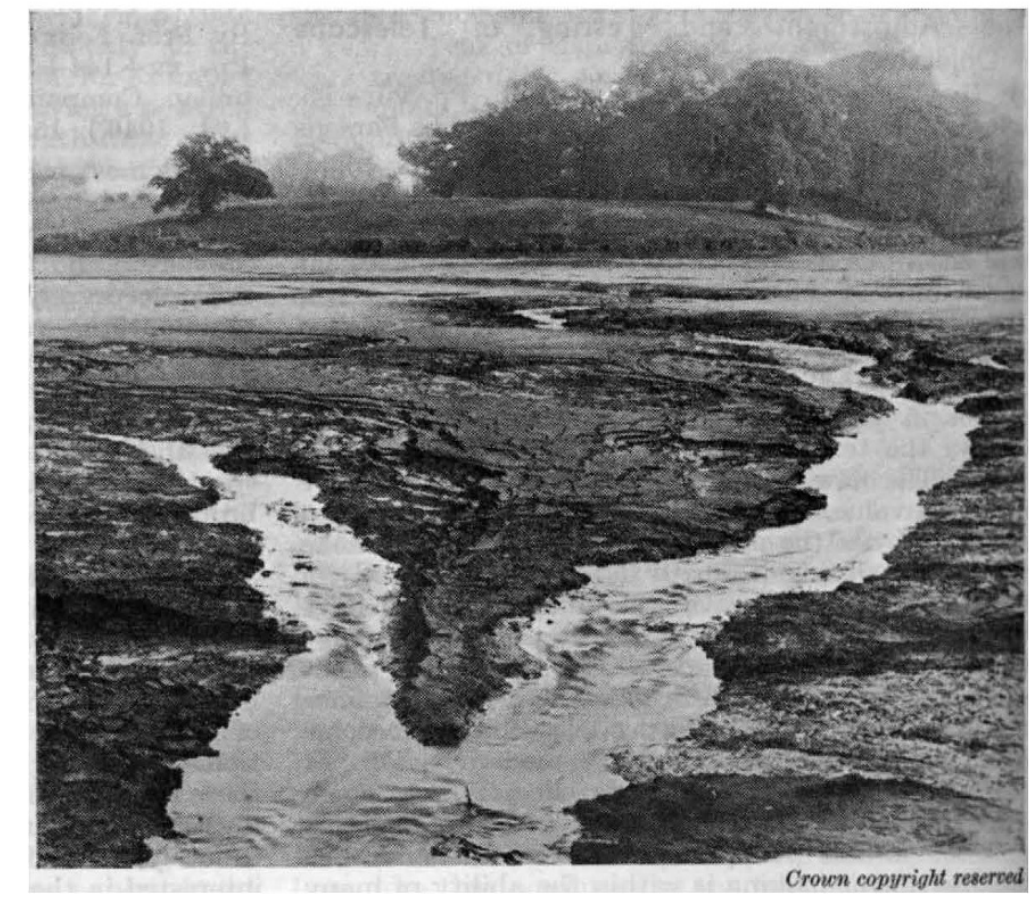

Fig. 1. Drainage channels produced in the bed of Binley Lake

(C) 1948 Nature Publishing Group 


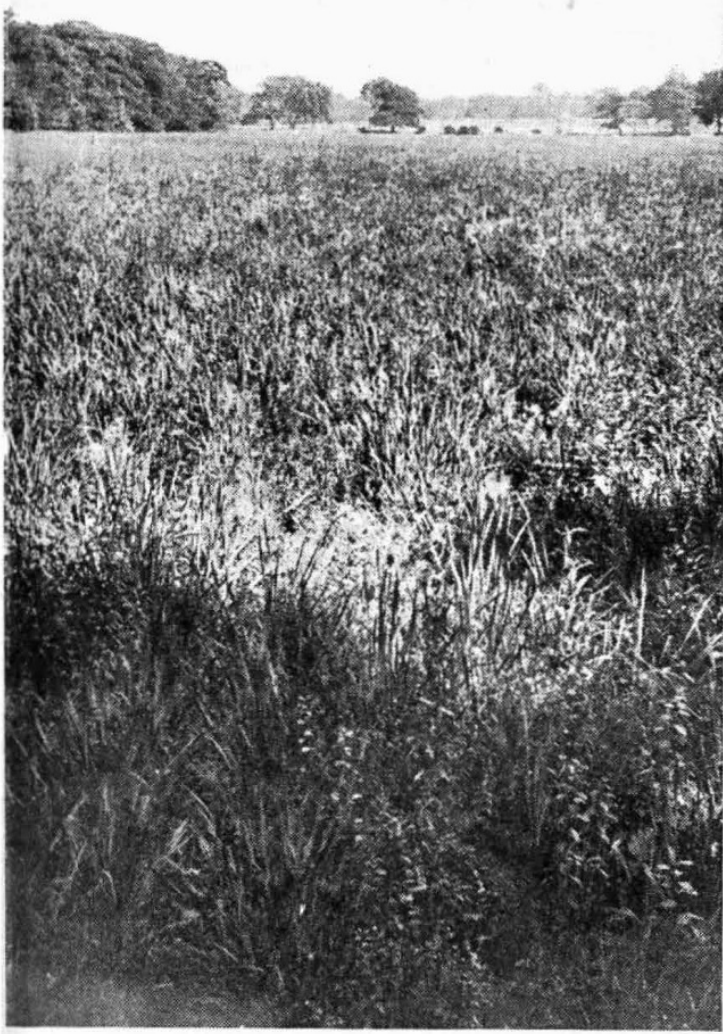

Crown copyright reserved

Fig. 2. Vegetation Covering the BED OF BINLEY IAKE TEN MONTHS AFTER DRAINING

re-stocked. It was considered that until the Lake was reasonably clear of rotting vegetation, the oxygen content of the water would be too low to justify re-stocking with fish. It was also doubtful whether 6-8 $\mathrm{ft}$. of water would be sufficient to kill the vigorous growth which had arisen during the two years the Lake had been empty.

The owners were therefore advised that the vegetation should be cut close down in the spring, the autumn and the following spring before the Lake was re-flooded. Compensation was based upon this suggestion, and allowance was made for a reasonable period before the Lake and its fish could be expected to have recovered full fishing value. The owners decided, however, not to incur the expense of cutting, and they re-flooded the Lake in October 1944, almost exactly two years after it had been drained.

A visit to the Lake in August 1947 showed that during two seasons a few men had been employed in pulling out the bullrushes and similar growth which showed above the surface. In March 1946 there were large areas of open water with belts of reedmace at the shores. Some eight thousand roach, bream, pike, rudd and tench were then put in; a further seven thousand, with some golden carp, were added in September 1946. All seemed well until in July 1947 a strong growth of hornwort (Ceratophyllum demersum) developed in almost every part of the Lake. The growth extended to the surface in many places, where it entrained a quantity of ordinary pond weed and made fishing almost impossible. The fish, however, appeared to thrive. No dead fish have been seen, and those caught show good growth and are in good condition.

The problem now is to find what action can be taken without injury to the fish to avoid the growth of weed in subsequent years.

Dr. W. B. Turrill and Mr. V. S. Summerhayes, of Kew, visited the Lake in December 1943, and a brief summary of their findings is appended.

\section{VEGETATION AFTER DRAINING}

\section{By V. S. SUMMERHAYES and DR. W. B. TURRILL}

A visit to Binley Lake was made on December 2, 1943, under the guidance of Mr. F. P. Knight, of the Directorate of Camouflage. The Lake had been drained and its bed was occupied by a dense growth of vegetation fairly uniformly spread over the whole area. The dominant plant was the reedmace (Typha latifolia), except in a few small patches where other species (mainly Phragmites communis and Carex sp.) had obviously established themselves, previous to the draining, in shallow water against the shore. The reedmace plants were up to $6-8 \mathrm{ft}$. in height, and a very large number of them were in full fruit. Though they were distributed over the whole lake bed, the mature plants of reedmace were somewhat denser in some parts than in others. In places willows (Salix caprce and $S$. viminalis) had become established and were $8 \mathrm{ft}$. tall. Locally these willows were abundant. The reed grasses Phragmites communis and Glyceria maxima occurred in a few places, and many marsh and some dry-land species were listed as present in one to several individuals. It was fully established, from the morphology of the Typha and other plents, that this remarkable growth of vegetation had occurred within one year. The botanical evidence was in complete agreement with the dated records that the fruiting Typha plants had developed from seedlings in less than twelve months, a surprising rapidity of growth from establishment on bare mud.

The vegetation was only partially closed. In many places, leaves of separate plants touched or overlapped, but there was mostly bare mud between individual plants. On this mud were innumerable seedlings of Typha, low-growing marsh plants, some in flower or fruit, and mosses. The presence of mosses was not unexpected; but the species represented were mostly well-known dry land ones. Far and away the most abundant was a form of Funaria hygrometrica, which sometimes appeared in continuous patches a foot or more square, but more often in smaller clumps. Other species present in fair quantity, but scattered throughout much of the area of the lake bed, were : Barbula unguiculata, B. tophacea, Bryum argenteum, and Bryum sp. (barren). Small quantities of Webera carnea and Dicranella heteromalla were also noticed, and one patch of the liverwort Marchantia polymorpha was found near the inlet end of the Lake.

The reedmace which, at the time of the visit, had so largely occupied the mud, must have spread as seeds from near the top (inflow) end of the Lake, where there was an old-established community of this species forming what had evidently been a Typha swamp. No other Typha was found growing in or near the Lake, except the young plants and seedlings all less than a year old. 